\title{
Asking the Right Question: Specifying Your Study Question
}

\author{
Annie L. Raich ${ }^{1} \quad$ Andrea C. Skelly ${ }^{1}$ \\ ${ }^{1}$ Spectrum Research, Inc., Tacoma, Washington, United States \\ Evid Based Spine Care J 2013;4:68-71.
}

\section{Introduction}

The most important step in conducting a high-quality research study is to create a study question that will provide the guidance for the planning, analysis, and reporting of your study. The process of generating a novel, answerable study question seems like it should be simple at first blush. Perhaps your keen interest in a particular topic sparks an idea for a study that starts the creative process of hypothesizing and wondering "what if." It is a wonderful experience to witness or be caught up in the joys of such a process. Finding inspiration for a study may, however, be a challenge, and the study idea emerges, instead, with time after thoughtful consideration of a topic. In either scenario, in order for you to design and execute your study, honing your idea and hypothesis into questions that can be realistically studied is required, adding a level of complexity to what at first seemed simple.

Creating the final study question is a formal and iterative process: You create an initial study question by answering questions, defining parameters, getting feedback from colleagues, and conducting a limited literature search. Then you refine your question and define major aspects of your study by using a Patients, Intervention, Comparison, and Outcomes (PICO) table for treatment and diagnostic studies, or a Patients, Prognostic factors, and Outcomes (PPO) table for prognostic studies. By taking the time to complete these steps, you will have a good structure for your research study and will be able to proceed to the next part, a literature review.

\section{What Is a Study Question?}

A study question reflects an uncertainty that you want to try to resolve, perhaps an uncertainty about the effectiveness of an intervention or how well an intervention works in a specific patient population. It is the basis for your research study and presents the idea or ideas that are to be examined in your study. Everything included in your study must relate to your study question(s) and study objective. It gives infor-
Address for correspondence Andrea C. Skelly, Spectrum Research, Inc., Atrium Court, 705 S. 9th Street, Tacoma, WA 98405, United States (e-mail: andrea@specri.com).

mation about the patients to be studied, interventions to be compared, and primary outcomes to focus on.

Your general study question can come from several places. ${ }^{1}$ You or others in your field might have observed a pattern of positive or poor outcomes or problems regarding a current treatment. Recent advances or technologies might spawn questions about their safety or applicability to different patient populations. Technologies in other fields might have potential for use in your clinical field. Or, you think that other treatments might perform better than what is currently practiced. Unfortunately, high quality, novel, and answerable study questions do not usually just appear. The inspiration for the study may emerge with time as you confer with colleagues, listen to lectures at professional meetings, or even as you critically appraise literature on a given topic. Frequently, study ideas build on previous research and are honed by working collaboratively with mentors and colleagues. Once you have a general idea of what you would like to research, the process of crafting your study begins with carefully forming and focusing an answerable question.

\section{The Process of Creating an Effective Study Question}

\section{Step 1: Draft a Preliminary Study Question}

The first step is to draft a simple clinical question you would like to answer or a hypothesis you would like to explore. What do you think the answer to that clinical question might be? Why do you think it may be important to evaluate this question?

\section{Step 2: Focus Your Study Question}

Now you can start the process of focusing your question. The following is an example of creating a preliminary study question. Suppose you are interested in several treatments for cervical myelopathy. - Table 1 shows an example of progressing from a broad study question to one that is more focused. Note that in creating a more focused study question, we have been more specific on aspects of the (c) 2013 Georg Thieme Verlag KG Stuttgart · New York
DOI http://dx.doi.org/ 10.1055/s-0033-1360454. ISSN 1663-7976. 
Table 1 Improving study question focus

\begin{tabular}{|l|l|l|}
\hline Study question too broad & Study question somewhat more answerable & Study question with improved focus \\
\hline $\begin{array}{l}\text { What is the comparative } \\
\text { effectiveness of laminoplasty } \\
\text { versus laminectomy and fusion? }\end{array}$ & $\begin{array}{l}\text { What is the comparative effectiveness of } \\
\text { laminoplasty versus laminectomy and fusion } \\
\text { for adults with cervical myelopathy? }\end{array}$ & $\begin{array}{l}\text { What is the comparative effectiveness } \\
\text { of laminoplasty versus laminectomy } \\
\text { and fusion for adults with myelopathy } \\
\text { due to spondylosis in the cervical spine? }\end{array}$ \\
\hline
\end{tabular}

diagnostic condition (myelopathy due to spondylosis) and the patient population (adults).

\section{Step 3: Complete a PICO or PPO Table}

Add specifications to your study question using a PICO or PPO table to further refine it. While the more focused study question above is an improvement, there are some additional questions you should ask:

- What types of patients and pathologies do you want to study or exclude from the study?

- What variations of the treatments or interventions do you want to consider or exclude from the study?

- What specific outcomes or complications are the most important to measure and evaluate?

The PICO/PPO system provides a framework for further refinement based on these questions. A PICO/PPO table will help you to consider what should be included in your study and what should not be included. Your final PICO/PPO table is an aid to further refine your study question, define inclusion and exclusion criteria, highlight the interventions and outcomes you will measure, and provide the groundwork for a focused literature search. Note that a PICO table is used for treatment studies and a PPO table is used for prognostic studies. A PICO table is used as the example in this article.

Consider the following issues when creating your PICO table:

- Patients: Consider factors related to the condition, demographics (e.g., age, gender), behaviors (e.g., smoking), medical history (e.g., previous treatment, medications, general health factors, comorbidities), factors associated with treatment selection (e.g., severity or location of condition), and other factors that might be relevant to treatment selection or outcomes. For most studies, it is important to define a fairly homogeneous patient population, especially if there are any factors that might influence the outcome other than the intervention you are evaluating. For example, note that in the PICO table below, we are including patients with spondylosis and excluding patients with OPLL. If the condition itself (spondylosis or OPLL) can influence the outcome, it is better to restrict the study population to one condition. However, keep in mind that a restricted study population can limit bias in your study yet will also limit the generalizability of your findings to a patient population in a clinical setting.
- Intervention: Make sure you specify variations of the procedures (e.g., approach, number of levels, use of specific devices, grafting) as being included or excluded. If there are variations of the procedure that could influence results, think carefully about their inclusion.

- Comparison: Specify the alternative treatment to which the intervention is compared. Again, are there variations that should be excluded?

- Outcomes: Be specific and aim for the most important outcomes. They can be patient-reported (e.g., pain, function, quality of life) or clinical outcomes (e.g., nonunion, complications, reoperation, death). List the primary outcome of interest first; this outcome provides the focus for your study, the data collection, and the sample-size estimate. Then list secondary outcomes that might provide valuable contributions to your overall study results.

- Table 2 is an example of a PICO table for your study question, "What is the comparative effectiveness following laminoplasty versus laminectomy and fusion for adults with myelopathy due to spondylosis in the cervical spine?"

\section{Step 4: Refine Study Question and Conduct Preliminary Literature Search}

Now you can use your completed PICO table to refine your study question and to conduct a quick preliminary literature search. It is important to find out what is currently known and not known about your research topic, what has already been published on this topic, and what gaps exist that your research can fill, whether it be a type of intervention that has not been studied, a particular group of patients who have not previously been included in studies, or an outcome that has not been measured but is important to patients. This initial literature search helps you hone your study question further and may help you determine if it is realistic to answer in a single, focused study. The PICO framework is also helpful for getting feedback from potential co-investigators/colleagues to further refine your study question.

\section{Step 5: Consider Additional Questions}

By this point, you should have not only a solid study question, but at least a preliminary idea of how you might approach answering it, and there are some additional questions to consider for another round of refinement.

To be more specific in your study focus, consider these additional questions: 
Table 2 Example of a PICO (Patients, Intervention, Comparator, Outcomes) table for formulating a study question

\begin{tabular}{|c|c|c|}
\hline & Inclusion & Exclusion \\
\hline $\begin{array}{l}\text { Patients } \\
\text { What patient group do you } \\
\text { want to include? }\end{array}$ & $\begin{array}{l}\text { Symptomatic adults with } \\
\text { cervical myelopathy } \\
\text { due to spondylosis }\end{array}$ & $\begin{array}{l}\text { - Patients under } 18 \text { years of age } \\
\text { - Ossification of the posterior } \\
\text { longitudinal ligament (OPLL) } \\
\text { - Tumor } \\
\text { - Trauma } \\
\text { - Infection } \\
\text { - Deformity }\end{array}$ \\
\hline $\begin{array}{l}\text { Intervention } \\
\text { What surgical treatment, procedure, } \\
\text { or implants are you interested in? }\end{array}$ & Cervical laminoplasty & \\
\hline $\begin{array}{l}\text { Comparison } \\
\text { What is the comparison treatment? }\end{array}$ & $\begin{array}{l}\text { Cervical laminectomy } \\
\text { and fusion }\end{array}$ & \\
\hline $\begin{array}{l}\text { Outcomes } \\
\text { What outcomes are you interested } \\
\text { in (e.g., pain, function)? }\end{array}$ & $\begin{array}{l}\text { - JOA recovery rate (primary outcome) } \\
\text { - NDI } \\
\text { - Neck or arm pain } \\
\text { - SF-36 } \\
\text { - Complications, including CSF leakage, } \\
\text { dural tear, and C5 palsy }\end{array}$ & $\begin{array}{l}\text { - Radiographic outcomes } \\
\text { - Economic, cost-effectiveness }\end{array}$ \\
\hline
\end{tabular}

Table 3 Final study question

In symptomatic adults with cervical myelopathy due to spondylosis, does laminoplasty improve the severity of myelopathy (as measured by the JOA recovery rate) compared with laminectomy and fusion at 12 months?

or, more specifically

In symptomatic adults with cervical myelopathy due to spondylosis, does laminoplasty lead to a minimum $75 \%$ JOA recovery rate (from baseline to 12 months) more frequently than after laminectomy and fusion?

- What might constitute a clinically meaningful improvement?

- What time frame will be important? Are you looking at outcomes that are short-term or long-term to evaluate the effects?

- Is there a specific hypothesis that you would like to test?

After considering the questions above, you can refine your study question further ( - Table 3 ).

\section{Step 6: Perform a More Complete Literature Search}

Now that you have created a clear, focused, answerable study question and a PICO or PPO table as the framework for your study, you can proceed to a more complete literature search. It is important to solidify your understanding of what is known about your research topic, what gaps in knowledge need to be filled, and what is the best study design to answer your study question. The AO SMART Handbook for Spine Clinical Research $^{2}$ is a good reference for planning your research study, including formulating your study question, conducting a literature search, and selecting an appropriate study design.
Additionally, you can use a previously published EBSJ article as an aid to literature search. ${ }^{3}$

\section{Conclusions}

1. Great study ideas take time to formulate. Familiarity with the strengths and limitations of the current literature, participation in professional meetings and collegial exchanges are probably the best breeding grounds for generating great, new study ideas. It may take time for the input from such sources to coalesce into an inspired thought that ignites the creative process.

2. Your study begins with developing a researchable study question, which is an iterative and deliberate process. You might have to go through multiple iterations in the process of refining your study question into something that is novel and answerable.

3. The PICO/PPO framework is invaluable for helping you refine your study question, setting the stage for both preliminary and more complete literature searches, and for laying the groundwork for your study. 
4. The more focused your study question is, the higher the likelihood that you will be able to find a meaningful answer to it.

5. The more thought and effort you put into the initial planning of your research study, especially the creation of a focused, answerable study question and PICO/PPO framework, the higher quality your research study is likely to be and more likely you are to find an answer to that question!

\section{Funding}

This article was funded by AOSpine.

\section{References}

1 Cummings SR, Browner WS, Hulley SB. Conceiving the research question. In: Hulley SB, Cummings SR, Browner WS, Grady DG, Newman TB, eds. Designing Clinical Research. Philadelphia: Lippincott Williams and Wilkins; 2007:17-26

2 Lee MJ, Norvell DC, Dettori JR, Skelly AC, Chapman JR, eds. SMART Handbook for Spine Clinical Research. New York: Thieme; 2013

3 Ecker ED, Skelly AC. Conducting a winning literature search. Evid Based Spine Care J 2010;1(1):9-14 